\title{
GROWTH OF RAT LEPROSY BACILLUS IN TISSUE CULTURE Dr. Frank Hawking
}

National Institute for Medical Research, Mill Hill, London, N.W.7

The purpose of this paper is to describe investigations on the cultivation of the organism of rat leprosy, Mycobacterium leprae murium, in tissue culture. The first attempt thus to cultivate this organism was made by Zinsser \& Carey in 1912. Since then there have been many other attempts (see Gavrilov, 1939; Kudicke \& Vollmar, 1937; Dharmendra \& Lowe, 1937; and the review by Lowe, 1937), but it is usually considered that successful cultivation was not achieved.

The present paper deals with the attempt to grow the organism in macrophages, and the experiments were undertaken as the result of the suggestion of Dr. R. J. W. Rees of this Institute. Dr. Rees has in the meantime published a short description of successful experiments by another method (Rees \& Wong, I958).* Grateful acknowledgments are due to him for the stimulus of the initial proposal, for supplying the strain or organisms, and for advice about obtaining macrophages from the peritoneum.

\section{Methods}

Use was made of the strain of $M$. leprae murium which has been maintained at this Institute for many years. The method of tissue culture employed was similar to that used for cultivating various kinds of intracellular protozoa such as the exoerythrocytic forms of Plasmodium gallinaceum (Hawking, 1945, I95 I). Briefly, small Carrel flasks (diameter $3.5 \mathrm{~cm}$.) were used. A thin layer of fowl plasma was spread over the floor and I-4 pieces of cover slip, $0.5 \mathrm{~cm}$. square, were embedded upon it: Small pieces of tissue were mounted on top of the glass slips, being held in place with a drop of plasma. The fluid medium is described in the text. To examine the growth of the tissue the slips were removed from the flask, fixed, stained with Ziehl-Nielsen haematoxylin and mounted tissue downwards on a slide. In the later experiments the flasks were prepared with one or two pieces of cover slip which, together with the floor, were coated with a thin layer of plasma and embryo extract. Macrophages from the rat's peritoneum were suspended in fluid medium, and $3 \mathrm{ml}$. of the suspension were added to each flask.

Most of the cultures were incubated at $35^{\circ} \mathrm{C}$, but some flasks were kept at $30^{\circ} \mathrm{C}$. The cells grew well at this lower temperature

- Wallace, Elek, and Hanks (1958) have reporterl similar experiments in which limited multiplication of the organism was ohtained. This information became available since the present paper was submitted for publication: see references. 
and probably survived better than at $35^{\circ} \mathrm{C}$, but presumably the growth of the bacilli would also be slower. In the later work the total number of bacilli in a flask was estimated by a method using citric acid as described by Sandford (1954). The Carrel flask was almost filled with about $\mathrm{I} 2 \mathrm{ml}$. of $\mathrm{I} .8$ per cent citric acid. The floor was scraped with a spatula to loosen tissue and plasma clots and the flask was then shaken at $35^{\circ} \mathrm{C}$. for several hours. In some cases, if shreds of tissue were still visible, the fluid was further ground in a tissue grinder until a homogeneous suspension was obtained. The fluid was then made slightly alkaline by adding concentrated caustic soda; unless this is done the bacilli do not take Ziehl-Nielsen stain. Horse serum ( $\mathrm{I} \mathrm{ml.)} \mathrm{was} \mathrm{added} \mathrm{to} \mathrm{improve}$ adhesion of bacilli to the slides. Samples of $20 \mathrm{cmm}$. were withdrawn and spread on glass slides inside a square measuring $2.0 \mathrm{~cm}$. The numbers of bacilli lying within three strips $0.1 \mathrm{~mm}$. wide were counted with an oil immersion objective; and appropriate calculations were made to obtain the number in the original suspension.

In some experiments small quantities of mycobactin or of extract of rat leproma were added to certain flasks as I-3 drops of fluid every time the medium was changed. The mycobactin was a partially purified preparation kindly provided by Dr. G. A. Snow. For use, roo mg. was dissolved in $\mathrm{I} \mathrm{ml}$. of ethanol with heat and then $60 \mathrm{ml}$. Ringer solution was quickly added. The resultant opalescent fluid was sterilised by autoclaving. Concentrations of $0.3 \mathrm{mg}$. per Ioo $\mathrm{ml}$. tended to be toxic to the cells, but concentrations of $0.02 \mathrm{mg}$. per $100 \mathrm{ml}$. were well tolerated. The leproma extract was prepared by extracting about $\mathrm{I} 00 \mathrm{~g}$. of rat lepromatous tissue with methanol at $35^{\circ} \mathrm{C}$. for ro days. The fluid was then decanted and concentrated by evaporation until a yellow waxy mass remained. A small quantity of this (300 mg.) was redissolved in $0.5 \mathrm{ml}$. alcohol, which was then diluted with $40 \mathrm{ml}$. Ringer and sterilized by autoclaving. Concentrations of ro $\mathrm{mg}$. in $100 \mathrm{ml}$. were well tolerated by the cells. To test whether the bacilli in a culture were alive or dead, inoculations were made subcutaneously into rats. In the case of fluid, the inoculation was made directly, or after concentration by centrifuging. In the case of tissue, the whole piece of cover slip was inserted. If the material contained viable bacilli, lepromatous nodules usually became palpable at the site of inoculation after about 6 months, but all animals were observed for 12 months before being discharged as uninfected.

\section{Results}

Various preliminary experiments were made to study the rate of multiplication of the bacilli in vivo, and also their survival outside the body under various conditions. In one experiment, a 
standard dose of bacilli was injected intravenously into a large group of rats. After a few days 4 rats were killed and the number of bacilli in the spleen was estimated, and further groups of 4 rats were killed at fortnightly intervals. During the of this experiment, the bacilli multiplied at the rate of one division every 9 days, but over a period of 7 weeks they multiplied at the rate of one division every 15 days. In a second experiment, bacilli were injected into the testes of rats and the rates of multiplication in the testis was estimated in the same way; over a period of 10 weeks, multiplication proceeded at the rate of one division every I3 days. Accordingly it could not be expected that multiplication in vitro would be quicker than this, and probably it would be much slower.

The number of bacilli required to produce an infection in rats was estimated by making up a suspension of bacilli which was counted in the usual way. Serial dilutions $\mathrm{x}$ I/IO were made and standard quantities were inoculated subcutaneously into groups of 4 rats. The rats which received $10^{8}$ bacilli showed slight lumps after 3 months, and marked nodules after 4 months; those with ${ }^{4} 0^{4}$ bacilli showed nodules after 6 months; those with $\mathrm{IO}^{3}$ or $\mathrm{IO}^{2}$ bacilli showed nodules after 6 and 7 months, and those with nominally Io bacilli all showed definite nodules after 8 months. Clearly a very small number of bacilli is sufficient to initiate an infection, and subcutaneous inoculation into rats is a sensitive test for the presence of viable bacilli.

The resistance of the bacilli to drying was tested by placing a drop of a suspension of bacilli (containing about 300 million bacilli per drop) on each of many small pieces of filter paper $0.5 \mathrm{~cm}$. square and then storing them individually in open test tubes in a hot room at $35^{\circ} \mathrm{C}$. After suitable intervals, the pieces of paper were embedded subcutaneously into rats. Rats which received paper immediately or after drying for 5 hours showed nodules after 4 months; those receiving papers after drying for I day showed nodules after 5- 6 months; those receiving papers after drying for 3 or 8 days showed nodules after 7 -II months; and those receiving papers after drying 16 days showed no nodules even after 14 months. Apparently most of the bacilli are killed by drying for I day, a few resist drying for 8 days and none resist for 16 days.

The survival of bacilli in tissue culture media without living cells was investigated by making suspensions of peritoneal cells and bacilli as described below and incubating the cells in a dense suspension for 24 hours so that the cells would be killed. The mixture of dead cells and bacilli was then set up in Carrel flasks in the usual way and incubated at $35^{\circ} \mathrm{C}$. At suitable intervals fluid from the flasks was injected subcutaneously into pairs of rats. In a few cases 
fluid which had been incubated for 6 days produced nodules atter 6 months, but in most of the experiments viable bacilli were not found after 6 or more days. The death of the bacilli might have been due to the absence of favourable conditions or to a direct toxic action of the serum in the medium. These results are in contrast to those obtained by proper tissue culture technique.

In other experiments investigations were made on the effect of cortisone (2 mg. per roo g. s.c. on alternate days for 3 months) upon the development of nodules in rats. In one experiment the rats which received cortisone developed nodules earlier and larger than the controls without cortisone; in a second experiment, there was no significant difference between the two groups. Other experiments showed that $M$. leprae murium can develop in the cotton rat (Sigmodon hispidus) but the lesions are much smaller than in ordinary rats.

\section{Early experiments with tissue culture}

These were made with small pieces of tissue, approximately I cmm., cut from the edge of lepromata. The fluid medium consisted of 20 per cent rat serum, 3 per cent embryo extract, 67 per cent Tyrode and a small amount of phenol red. Fluid was changed every 4-5 days. The fibroblasts grew vigorously and many were still healthy after 7 weeks; they contained practically no bacilli and it was concluded that they were not desirable in the cultures. The macrophages were less vigorous, but in some cultures a few survived up to 7 weeks They usually contained great numbers of bacilli, but it was impossible to decide from the microscopic appearances whether these bacilli had multiplied in the cell, or whether they had merely accumulated by ingestion. In addition there were great numbers of bacilli lying extracellularly, presumably liberated by the breakdown of cells. In some experiments implants of clean tissue from the spleen or liver of baby rats were inserted into flasks containing implants from lepromata. When examined one or more weeks later the colonies growing around the clean implants included macrophages which contained bacilli; but it was impossible to tell from which colony these macrophages had originated. In some experiments baby rats were inoculated intraperitoneally with bacilli, and a week later tissue cultures were made from the surface of the spleen and liver. The cells grew well, and bacilli could be found in them after several weeks, but this type of culture seemed to offer no particular advantage. Inoculations into rats during these experiments showed that the bacilli survived and were still infective after the longest period studied (54 days), provided that living cells (macrophages) were also present. In flasks where the implant had failed to grow, bacilli were dead after 24 days, although they were still alive after 7 days. 
During these experiments it- became clear that by this technique it would be difficult to show whether successful culture was being achieved, since it was hard to estimate the number of bacilli inserted into a flask at the beginning of an experiment, in order to compare it with the number present at a later date. Accordingly later experiments were made with macrophages obtained from the rat's peritoneum.

\section{Later experiments}

Macrophages were obtained from the peritoneum of a rat by a method similar to that described by MacKaness (I952). Briefly, Io $\mathrm{ml}$. sterile liquid paraffin was injected intraperitoneally into a large rat. Two or three days later a suspension of bacilli was prepared by grinding down a suitable leproma, mixing with Ringer, centrifuging off the coarse deposit, and taking the supernatant fluid. About $15 \mathrm{ml}$. of this fluid (plain or diluted) was injected intraperitoneally into the rat which had received paraffin. Two to three days later still the rat was killed and the peritoneum was washed out with cold citrate saline. The washings were centrifuged and the deposit of cells was washed once in citrate saline and then suspended in nutrient medium. After counting the cells and adding more fluid to obtain a suitable density $(8,000$ cells per $\mathrm{cmm}$. $), 3 \mathrm{ml}$. of the fluid was placed in each Carrel flask. The flasks already contained a thin layer of fowl plasma (plus a little embryo extract to promote clotting) on the floor and one piece of cover slip for sampling. The flasks were then incubated at $35^{\circ} \mathrm{C}$. as usual. The fluid medium used in these later experiments consisted of horse or rat serum 40 per cent, Tyrode's solution 60 per cent, 50-100 units of penicillin per ml., and enough phenol red to give a red colour. The fluid was changed three times a week. Enumeration of the bacilli was performed both by spreading $20 \mathrm{cmm}$. of the fluid inserted into the flasks on a slide as described above, and also by taking two of the flasks after one day and digesting the total contents with citric acid as described above.

The cells cultivated by this procedure were almost all macrophages. In some flasks fibroblasts did appear and occasionally they became numerous, but in most flasks they remained inconspicuous. The cells initially formed a close covering over the floor of the flask, but after three weeks they were less numerous, although still apparently healthy; and after 4-5 weeks they usually became degenerate and diminished considerably in number. In the later experiments of this series, when it was seen that the cells were diminishing in number and in health, a fresh supply of macrophages, without bacilli, was obtained by the method described above and added to the flask when the nutrient medium was being changed. The new cells seemed to settle down readily on top of 
the old colony, ingesting any bacilli which might be available in distintegrating cells of the earlier generation. This addition of fresh macrophages can be repeated as often as is desired. One flask was maintained in this way for 4 months with 4 lots of new cells. Provided that there is no infection by bacteria resistant to permissible antibiotics, it seems that a substrate of vigorous macrophages can be maintained indefinitely by this technique. In order ot avoid undue loss of the bacilli during changing of the fluid medium, which takes place at an increased rate when the cells are degenerating and disintegrating, it is advisable to insert new cells as soon as the earlier cells show the least sign of diminution. During the maintenance of these cultures the fluid medium was changed three times a week (as said), and on each occasion there is the possibility of losing a smaller or larger number of bacilli. The importance of this factor was not appreciated until the latest period of this work. In one case, in a flask which had been maintained for over 2 months and which probably contained about 3 million bacilli at this time, the loss on each change (as estimated from examination of the fluid removed) was about 100,000 bacilli, i.e. about 3 per cent of the total number present. If the cells are degenerating, or if part of the plasma clot flakes off, the loss can be much greater. During most of this work no notice was taken of this possibility of loss, until one day fragments of fibrinous clot, which had been removed while changing the fluids from two flasks, were examined and were found to contain dense masses of bacilli.

After various preliminary trials an experiment consisting of 29 flasks was set up, I9 with horse serum and Io with rat serum. Two flasks were sacrificed after one day and showed that there were 270 million bacilli per flask present. Forty-two days later a small floating piece of fibrin, which had been removed from one of the flasks (I66) during changing, was examined and it was found to contain enormous numbers of bacilli. This flask and two others were then terminated for examination by removal of the cover slip for microscopical inspection and by digesting the remaining contents with citric acid. One of these flasks ( 169 , which had received leproma extract) was found to contain 354 million bacilli, plus a clot containing dense masses of bacilli; no new cells had been added to this flask. The second (II6, which had received mycobactin) contained 2IO million bacilli, plus a clot which contained enormous numbers of bacilli, mostly still inside cells. The third (I6I) contained 132 million bacilli, plus a big clot with large masses of bacilli. Since these flasks initially contained only 270 million bacilli and since a large but unmeasurable number of bacilli were known to have been lost during changing, it was considered that multiplication of the bacilli had occurred certainly in flask I69 and most probably 


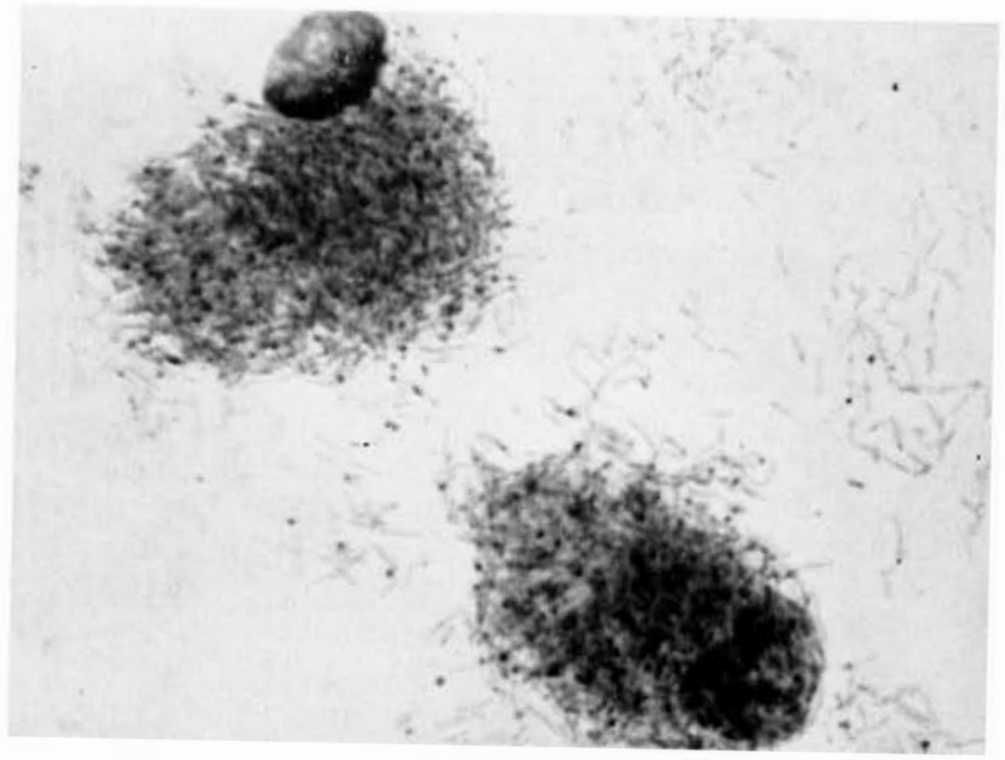

Fig. I. Two large macrophages full of bacilli. Smear of clot from flask 166 after culture for 42 days.

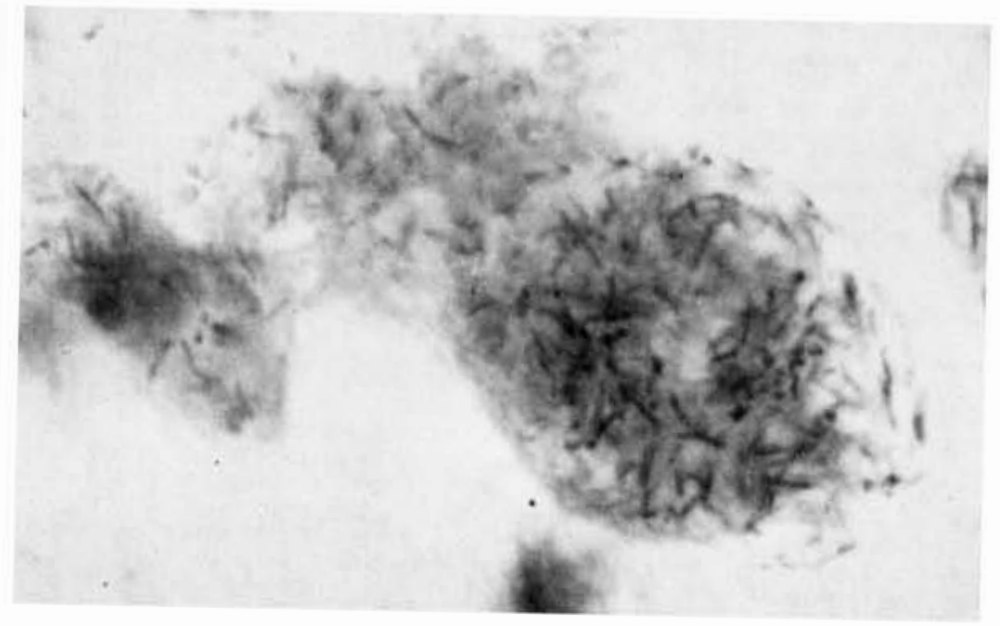

Fig. 2. Bacilli in large cell, after cultivation for 44 days (flask 16I). 


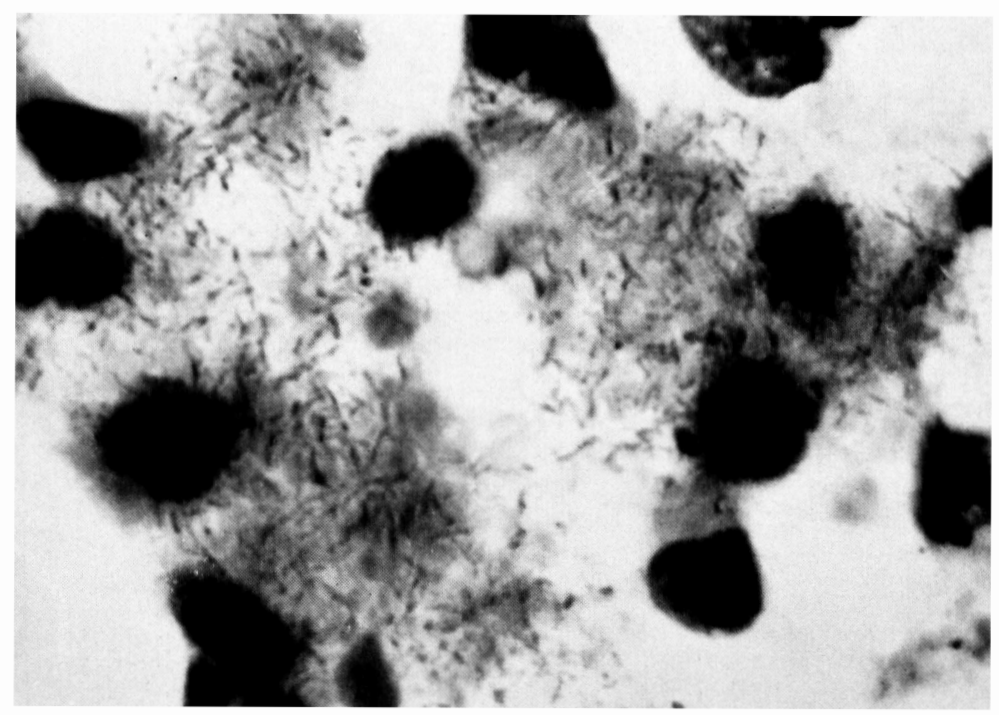

Fig. 3. Bacilli in cells after cultivation for 53 dais (fask 17I). Stained with Ziehl-Nielsen and haematoxylin. Magnification x 2,200. 
in the others also. The microscopic appearances on the cover slip (described below) also supported this interpretation.

At this point circumstances necessitated the termination of the work, and the existing cultures were killed for examination. Among the flasks which were thus terminated 52 days after the start, one flask (I68, which had received leproma extract) contained 550 million bacilli, which was twice the number initially present; also many bacilli had presumably been lost during the 23 changes of fluid medium. Other flasks contained 235, 212, 2 I4 million and similar numbers. All these flasks had been set up with horse serum. One flask which had been set up with rat serum contained 280 million; apparently the use of rat serum (instead of horse serum) is not sufficiently advantageous to outweigh the greater trouble of collection. On the other hand, 3 of the 4 flasks which received leproma extract had higher counts than those which did not, and all of the 4 flasks which received mycobactin had high counts; therefore the presence of these two substances probably promoted the multiplication of the bacilli, but it was not essential since other Hasks which did not receive them also yielded high counts. Similarly the addition of new cells, although highly advantageous in most cases, is not essential, since flask I69 (mentioned above) showed clear evidence of multiplication although no new cells had been added.

On microscopic examination of the slips removed from the flasks, most of the cells were found to be macrophages. Giant cells with several nuclei occurred fairly frequently; fibroblasts were sometimes present in small numbers. The macrophages and giant cells contained varying numbers of bacilli; in some cultures and some areas the cells were distended by great masses of them. The bacilli appeared healthy. Unless the cells were degenerating (or unless they had been broken by making a smear) all the bacilli were found inside the cells. In some places the plasma clot was much thicker than elsewhere, e.g. the original layer of plasma clot had become folded over; in other places the macrophages had invaded the plasma clot underneath the cover slip, between the slip and the floor of the flask. In both these places the cells contained especially large numbers of bacilli, and it seemed that they constituted particularly favourable sites for the development of the bacilli. Probably the cells were protected from movements of the fluid at these places, so that bacilli liberated by disintegration of a cell would have a good chance of being ingested by another cell before they were washed away; alternatively, bacilli might be favoured by the lower concentration of oxygen which might be expected in such sites. (A low concentration of oxygen is favourable to the survival of trypanosomes in vitro and the same may well 
be the case in the cultivation of $M$. leprae mursum). As regards the infectivity of the bacilli found in these flasks, fluid removed from flasks 158 and 163 after 40 days culture was injected into a rat and produced a leproma after an incubation period of 5 months; similarly fluid removed from flasks $I_{52}$ and I53 after 42 days produced a leproma after a period of 6 months.

\section{Discussion}

In the experiments described above, the bacilli of rat leprosy have been maintained in cultures of macrophages for over six weeks. At the end of this time the bacilli appeared numerous and healthy, and they were infective to rats. Judging by the counts they had doubled their numbers in one flask, (even though considerable quantities had presumably been lost during the changes of nutrient fluid). The following suggestions may be derived from these experiments:-

(I) The addition of fresh macrophages at suitable intervals permits cultures of this type to be maintained practically indefinitely and the bacilli pass readily from one crop of cells to the next.

(2) A medium containing 40 per cent of serum is beneficial to the cells, and the bacilli can probably multiply in the presence of this amount of serum. It has been reported by Hanks (I952) and Hanks \& Gray ( I 954) that when bacilli are suspended in vitro, their respiration is impaired by substances present in serum; and Hanks has recommended that the presence of any, or of much, serum should be avoided during attempts to grow the bacilli in tissue culture. The above experiments suggest that this view is not wholly correct, as multiplication was probably obtained in the presence of 40 per cent serum. Since the bacilli are contained inside the cells and can pass from one cell to another (during the phagacytosis of degenerate cells by healthy ones) without significant exposure to hypothetical antibacillary substances in the serum, it is probably more important to provide conditions which are favourable to the growth of the cells than to provide those favourable to extracellular survival of bacilli. As intracellular parasites, the leprosy bacilli presumably depend upon the metabolism of the host cell for many important products and processes; and probably the multiplication of the bacilli will not occur unless the metabolism of the host cell is healthy and vigorous.

(3) The growth of the bacilli appears to be favoured by the presence of a thick plasma clot around the cells (see above); it might be advantageous to add fresh layers of plasma at suitable intervals during the maintenance of these cultures.

(4) During experiments of this kind it is important to estimate the number of bacilli removed from the flasks by the frequent changing of fluid medium and especially to examine any small clots 
which may escape during this procedure.

(5) Extract of lepromatous tissue and mycobactin probably promote the multiplication of the bacilli, although their presence is not essential; they deserve further investigation.

(6) The optimal temperature, whether $37^{\circ}, 35^{\circ}$, or $30^{\circ}$ should also be investigated, since in vivo the bacilli multiply best in the superficial and, therefore, cooler parts of the animal.

(7) Penicillin, e.g. roo units per $\mathrm{ml}$., seems not to interfere with the growth of the bacilli and it is certainly valuable in preventing the growth of contaminants.

(8) In the above technique, liquid paraffin was used to facilitate the collection of macrophages from the rat's peritoneum; although such a foreign substance would appear to be disadvantageous to the cells, it is conceivable that globules of paraffin inside the macrophages might promote the multiplication of the bacilli therein.

The cultivation of the bacillus of rat leprosy is of importance in so far as it may help in the cultivation of the bacillus of human leprosy. Judging by the present experiments it is suggested that in attempts to grow $M$. leprae a substrate of macrophages should be used, presumably obtained from the blood, and that this should be renewed at suitable intervals by adding fresh cells to the containers. It would be essential to count the number of bacilli at the start of the experiment (either before or after addition to the cells) and again at its conclusion. The concentation of serum in the medium should be adjusted so as to favour the survival of the cells, i.e. it should probably be high. A thick plasma clot surrounding the cells would probably be advantageous; leproma extract or mycobactin might be advantageous. Even under favourable circumstances the growth of the bacilli seems to be slow, so it would be necessary to maintain the cultures for long periods. Since M. leprae grows as an intracellular parasite in macrophages, and since macrophages can be easily grown in tissue culture, experience with other intracellular parasites suggests that the cultivation of the human leprosy bacillus ought eventually to be possible by a suitable tissue culture technique.

\section{Summary}

Attempts were made to grow the bacillus of rat leprosy in tissue culture, using a Carrel flask technique with macrophages from the rat's peritoneum as a substrate. In the most favourable culture the number of bacilli present in a flask doubled during a period of 52 days; in addition an unknown (but probably large) number of bacilli had been lost during 23 changes of the fluid medium. The microscopic appearances also supported the belief that multiplication of the bacilli had occurred in these cultures. After incubation for 42 days cultures were still infective to rats. The growth 
of the bacilli was favoured by the following factors in the technique: the fluid medium contain 40 per cent serum (horse or rat) to promote good growth of the cells; fresh supplies of uninfected macrophages were added as required (every 3-4 weeks), which would allow such cultures to be maintained indefinitely; a thick plasma clot around the cells; presence of mycobactin or of extract of leproma.

Other experiments showed that the bacilli doubled in vivo every I3-I5 days; very small numbers (nominally Io bacilli) were enough to infect a rat; most bacilli were killed by drying for I day, but some were not killed until after 8 days; they did not survive in tissue culture media at $35^{\circ} \mathrm{C}$. for more than 6 days unless viable cells were present.

\section{Acknowledgements}

Grateful acknowledgements are due to Mr. K. Broomfield for much technical assistance and to Mr. M. Young for the photography. REFERENCES

Dharmendra \& Lowe, J. (1937). Ind. J. Med. Res., 25, 835.

Gavrilov, W. (1939). Amn. Soc. belg de Med. trop., 19, 367.

Hanks, J. H. (1952). Internat. J. Leprosy. 20, 66.

HaNKS, J. H. \& Gray (1954). Ibid., 22, 147.

Hawking, F. (1945). Trans. R. Soc.trop. Med. Hyg., 39, 245.

HaWKING, F. (1951). Brit. med. Bull., 8, 16.

Kudickf, R. \& Vollman, H. (1937). Zt. f. Bakt.. Orig 140, 293, 1937.

L.OWE, J. (1937). Internat. J. Leprosy, 5, 311 and 463.

Mackiness, G. B. (1952). J. Path. Bact., 64, 429.

ReEs, R. J. W. \& Wong, P. C. (1958) Nature, Lond. 181, No. 4605, 359.

SANDFORD, K. K. (1954), Methods in Medical Research, 4, 219.

* Wallace, J. H., Elek, S. D., and Hanks, J. H. (1958) Proc. Soc. exฐ. IBiol. 97, 101. 